\title{
A Cyclic Voltammetric Study of Electrodes for Reverse Electrodialysis
}

\author{
Seo-Yoon Lee ${ }^{1}$, Dong-Ju Lee ${ }^{1}$, Kyeong-Ho Yeon ${ }^{2}$, Woo-Gu Kim ${ }^{2}$, Moon-Sung Kang ${ }^{1}$, and Jin-Soo Park ${ }^{1, *}$ \\ ${ }^{1}$ Department of Environmental Engineering, College of Engineering, Sangmyung University, 31 Sangmyungdae-gil, \\ Dongnam-gu, Cheonan, Chungnam Province 330-720, Republic of Korea \\ ${ }^{2}$ Taeyoung Engineering \& Construction Co. Ltd., 10-2 Yeouido-dong, Yeongdeungpo-gu, \\ Seoul 150-777, Republic of Korea
}

(Received July 9, 2013 : Accepted August 1, 2013)

\begin{abstract}
In this study, the electrochemical investigation of various electrodes for reverse electrodialysis using potassium ferrocyanide and potassium ferricyanide as a redox system was carried out. Cyclic voltammetry was the employed method for this electrochemical study. From the results of cyclic voltammograms for various electrode materials, i.e., Au, Vulcan supported $\mathrm{Pt}$, activated carbon, carbon nanofiber, Vulcan, the Vulcan electrode showed the lowest overpotential, but the Pt electrode having slightly higher overpotential obtained slightly higher anodic and cathodic current densities for the $\mathrm{Fe}(\mathrm{CN})_{6}{ }^{4-} / \mathrm{Fe}(\mathrm{CN})_{6}{ }^{3-}$ redox couple. The cyclic voltammograms for the Vulcan electrode confirmed very good electrochemical reversibility and kinetic behavior. As a result, among the electrode materials, the Vulcan electrode is the most promising electrode material for reverse electrodialysis.
\end{abstract}

Keywords : Reverse electrodialysis, Cyclic voltammetry, Redox couple, Vulcan, Electrode

\section{Introduction}

Salinity-gradient energy is a promising renewable energy source, and estimates from literature predicted coverage of over $80 \%$ of the current global electricity demand when applied in all river mouths. The natural runoff in coastal areas has a huge physical-chemical potential which is the result of the salinity-gradient between the mainly-fresh runoff and the receiving mainly-saline reservoirs. ${ }^{1)}$ Mainly, the energy is based on the Gibbs free energy of mixing of river and sea water. For example, the theoretical amount of energy from mixing $1 \mathrm{~m}^{3}$ sea water and $1 \mathrm{~m}^{3}$ river water at a temperature of $293 \mathrm{~K}$ is $1.4 \mathrm{MJ}$.

Reverse electrodialysis (RED) is one of the possible processes for generating energy from the salt gradient between river and sea water. ${ }^{2)} \mathrm{A}$ typical RED stack consists of a number of

*E-mail: energy@smu.ac.kr alternating cation and anion exchange membranes. The compartments between the membranes are fed in turn with a concentrated and a diluted salt solution, i.e., sea and river water, respectively. ${ }^{3)}$ As shown in Fig. 1, for a sodium chloride solution,

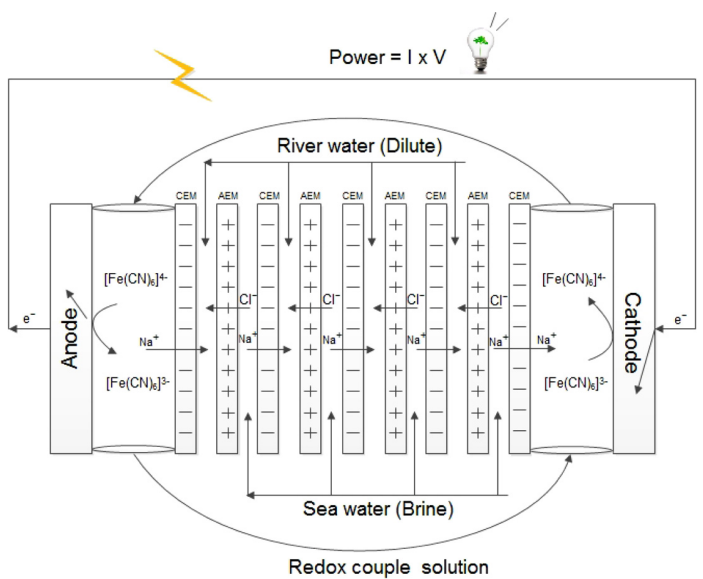

Fig. 1. Schematic diagram of reverse electrodialysis. 
sodium ions permeate through the cation-exchange membrane in the direction of the cathode, and chloride ions permeate through the anion-exchange membrane in the direction of the anode. Electroneutrality of the solutions in both the anode compartment and cathode compartment is maintained through redox reactions at the electrodes. As a result, electrons can be transferred from anode to cathode via an external electric circuit. This electrical current and the potential difference over the electrodes can be used to generate electrical power, when an external load is included in the circuit. ${ }^{1,3}$

Much effort should be devoted to minimize overpotentials or voltage drops for all energy conversion devices. Energy converted from salinity gradients is also dissipated in RED stacks: i) activation overpotential arising from electron transfer between redox couples and electrodes, ii) ohmic overpotential arising from ion-exchange membranes, solutions (i.e., river, sea water and electrode solution) and electrodes and iii) mass transfer overpotential arising from concentration polarization adjacent to the surface of ion-exchange membranes.

Electrode system for RED is a key component to determine the overall performance. In general, systems with dimensionally stable electrodes and a supporting electrolyte with the reversible $\mathrm{Fe}^{2+} / \mathrm{Fe}^{3+}$ or $\left.\left[\mathrm{Fe}(\mathrm{CN})_{6}\right]^{4-} / \mathrm{Fe}(\mathrm{CN})_{6}\right]^{3-}$ redox couple are often used. The potential difference needed for reduction of $\mathrm{Fe}^{3+}$ to $\mathrm{Fe}^{2+}$ on the cathode is counterbalanced by the oxidation of $\mathrm{Fe}^{2+}$ to $\mathrm{Fe}^{3+}$ at the anode. The $\mathrm{Fe}^{2+} / \mathrm{Fe}^{3+}$ ratio is kept constant by recirculation of the combined anolyte and catholyte through the electrode compartments which is called a homogeneous charge transfer reaction because all reactants are present in the same phase. This electrode systems allow no net chemical reactions, a theoretically zero equilibrium voltage, no energy consumption for a net chemical reaction, no loss of chemicals and no gas production under use of a pair of inert electrodes. However, all electrode reactions practically need additional energy consumption which is called overpotential or voltage drop. It depends on a type of electrode materials and electrolyte, the concentration of electrolytes, and so on. For better performance, i.e., power density, the overpotential arising from electrode reactions is necessary to be minimized as much as possible.

The present study is aimed at the determination of the optimum electrode material for the fixed redox couple for RED. Various electrode materials (i.e., Au, Vulcan supported Pt, activated carbon, carbon nanofiber, Vulcan) with the same redox couple $\left(\mathrm{Fe}(\mathrm{CN})_{6}{ }^{4-} / \mathrm{Fe}(\mathrm{CN})_{6}{ }^{3-}\right)$ were investigated for RED. The electrochemical behavior of the electrode materials was measured by applying cyclic voltammetric techniques and discussed.

\section{Experimental}

\subsection{Materials}

The reagents and materials used were deionized (DI) water, ethyl alcohol (Aldrich), Isoprophyl alcohol (Junsei), carbon nanofiber (Suntel, Republic of Korea), activated carbon (Samchun, Republic of Korea), Vulcan XC-72 (Cabot), Vulcan supported Pt (Pt/C) (Hispec 4000, Johnson Matthey), polyvinylidene fluoride (PVdF) solution $(0.03 \mathrm{wt} \%$ in PVdF and dimethylacetamide). All chemicals are reagent grade and are used as received. The electrode solutions of each 5, 10, 30, $50 \mathrm{mM}$ $\mathrm{K}_{4} \mathrm{Fe}(\mathrm{CN})_{6} / \mathrm{K}_{3} \mathrm{Fe}(\mathrm{CN})_{6}$ are prepared by dissolving the same concentration of $\mathrm{K}_{4} \mathrm{Fe}(\mathrm{CN})_{6}$ and $\mathrm{K}_{3} \mathrm{Fe}(\mathrm{CN})_{6}$ in $1 \mathrm{M} \mathrm{Na}_{2} \mathrm{SO}_{4}$.

\subsection{Electrochemical measurements}

Electrochemical measurements were carried out by cyclic voltammetry using a computerized potentiostat SP-150 (BioLogics, France) in a glass cell of $50 \mathrm{~mL}$ at room temperature. The $\mathrm{Ag} / \mathrm{AgCl}$ reference electrode was connected to the HaberLuggin capillary through a salt bridge containing $3.3 \mathrm{M} \mathrm{KCl}$ saturated solution. Among the electrodes (i.e., Au, Vulcan supported Pt, activated carbon, carbon nanofiber, Vulcan) investigated in this study, the $\mathrm{Au}$ novel metal electrode was directly used as working electrode, and was polished with powdered alumina and rinsed thoroughly with distilled water prior to each measurement. The other electrodes such as Vulcan supported Pt, activated carbon, carbon nanofiber and Vulcan were made by loading powder slurries on a working electrode at which 
polishing with powdered alumina and thorough rinsing with distilled water were done. The powder slurries were made by mixing $1 \mathrm{mg}$ of powder such as $\mathrm{Pt} / \mathrm{C}$, activated carbon, carbon nanofiber or Vulcan with $1 \mathrm{~mL}$ of the mixture of isoprophyl alcohol (IPA) and ethyl alcohol (7:3) mechanically for $5 \mathrm{~min}$ followed by ultrasonically for $20 \mathrm{~min}$. The $30 \mu \mathrm{L}$ of the mixture was loaded onto the surface of a working electrode and dried for $5 \mathrm{~min}$ by a drier. The $15 \mu \mathrm{L}$ of the PVdF solution was then added and dried for $5 \mathrm{~min}$ by a drier. The $\mathrm{Au}$ working electrode $\left(0.196 \mathrm{~cm}^{2}\right)$ and the $\mathrm{Pt}$ counter electrode were used. All potentials in this experiment are referenced against $\mathrm{Ag} / \mathrm{AgCl}$ (3.3 M saturated $\mathrm{KCl}$ ).

The three-electrode electrochemical chamber was assembled and filled with the redox couple solution of $50 \mathrm{mM} \mathrm{Fe}(\mathrm{CN})_{6}{ }^{4-} / \mathrm{Fe}(\mathrm{CN})_{6}{ }^{3-}$ in $1 \mathrm{M} \mathrm{Na}_{2} \mathrm{SO}_{4}$ as supporting electrolyte. The system is deoxygenated by purging with $\mathrm{N}_{2}$ for approximately $1 \mathrm{~h}$ and kept flowing $\mathrm{N}_{2}$ into the solution to prevent $\mathrm{O}_{2}$ dissolution during measurement. In the scanning range of potential from 0.758 to $-0.162 \mathrm{~V}$ (vs. Ag/ $\mathrm{AgCl}$ in $3.3 \mathrm{M}$ saturated $\mathrm{KCl}$ ), cyclic voltammetry was scanned to start from 0.758 via $-0.162 \mathrm{~V}$ by a scan rate of $20 \mathrm{mV} \mathrm{s}^{-1}$. Each measurement was repeated 10 cycles.

\section{Results and Discussion}

Cyclic voltammetry (CV) is the most versatile electroanalytical technique for the study of electrochemical behaviors of oxidation and reduction of electroactive species precisely. In a standard CV measurement, the potential of a system controlled between a working and a reference electrode is swept back and forth between two voltage limits while the current response between a working and a counter electrode is measured. The voltage sweep is generally linear with time, and the plot of the resulting current against voltage is called a cyclic voltammogram. An illustration of a typical $\mathrm{CV}$ wave form is shown in Fig. 2.

Fig. 3 shows the cyclic voltammograms of various electrodes, i.e., $\mathrm{Au}$, Vulcan supported $\mathrm{Pt}(\mathrm{Pt} / \mathrm{C})$, activated carbon (AC), carbon nanofiber (CNF), Vulcan, in the redox couple solution. All

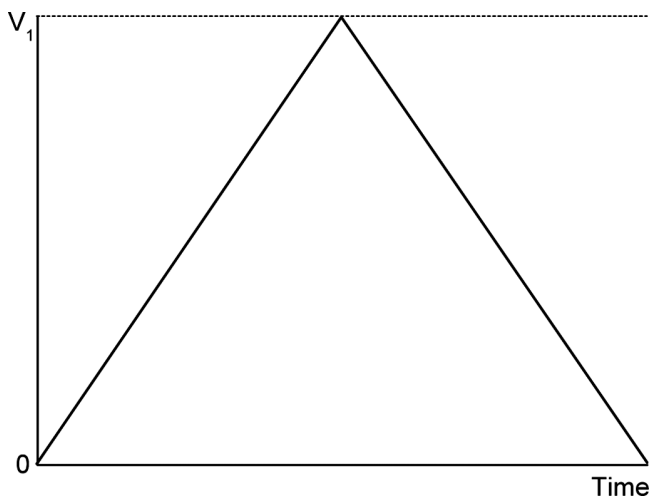

Fig. 2. Typical applied potential program of cyclic voltammetry $\left(V_{1}\right.$ is a switching potential).

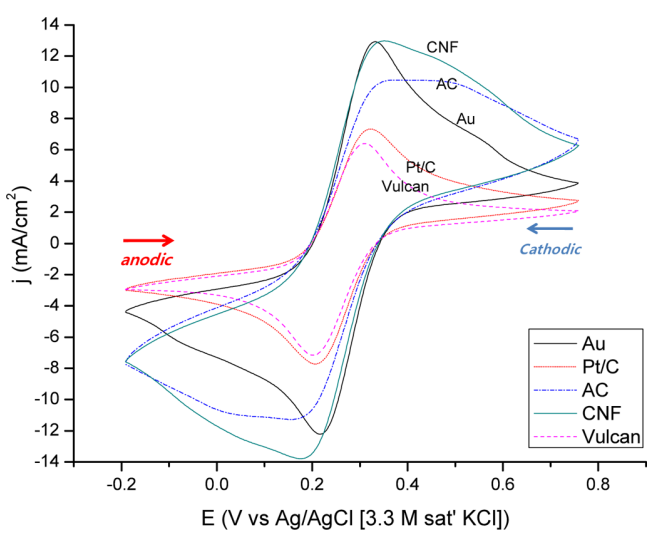

Fig. 3. Cyclic voltammograms of various working electrodes in $50 \mathrm{mM} \mathrm{Fe}(\mathrm{CN})_{6}{ }^{4-} / \mathrm{Fe}(\mathrm{CN})_{6}{ }^{3-}$ in $1 \mathrm{M} \mathrm{Na}_{2} \mathrm{SO}_{4}$.

voltammograms were obtained in the potential window in which water dissociation reactions such as hydrogen and oxygen evolution are not involved. Only the peaks from all the voltammograms are subjected to an anodic and a cathodic peak. Most of anodic and cathodic peaks are shown in the range of 0.31-0.35 and $0.15-0.22 \mathrm{~V}$ (vs. $\mathrm{Ag} / \mathrm{AgCl}$ in $3.3 \mathrm{M}$ saturated $\mathrm{KCl}$ ), respectively. This reversible electrochemical behavior is attributed to the following reversible reaction:

$$
\begin{aligned}
& \mathrm{Fe}(\mathrm{CN})_{6}{ }^{3-}+\mathrm{e}^{-} \rightarrow \mathrm{Fe}(\mathrm{CN})_{6}{ }_{6}^{4-}, \\
& \mathrm{E}^{\mathrm{o}}=0.162 \mathrm{~V} \text { vs. } \mathrm{Ag} / \mathrm{AgCl}
\end{aligned}
$$

in $3.3 \mathrm{M}$ saturated $\mathrm{KCl}$ at $25^{\circ} \mathrm{C}$.

The anodic and cathodic scans proceed the oxidation 
(the aforementioned backward reaction) from $\mathrm{Fe}(\mathrm{CN})_{6}{ }^{4-}$ to $\mathrm{Fe}(\mathrm{CN})_{6}{ }^{3-}$ and reduction (the aforementioned forward reaction) from $\mathrm{Fe}(\mathrm{CN})_{6}{ }^{3-}$ to $\mathrm{Fe}(\mathrm{CN})_{6}{ }^{4-}$. However, in case of $\mathrm{CNF}$ and $\mathrm{AC}$, there exist very broad anodic and cathodic peaks including a pair of sharp anodic and cathodic peaks which are shadowed. In addition, the magnitude of anodic and cathodic current density is not symmetric. Notwithstanding this, it is clearly shown that the anodic and cathodic curves (positive and negative current density, respectively) of the other electrodes are almost symmetric due to the reversibility of $\mathrm{Fe}(\mathrm{CN})_{6}{ }^{4-}$ and $\mathrm{Fe}(\mathrm{CN})_{6}{ }^{3-}$. The standard electrode potential of the aforementioned reaction is $0.162 \mathrm{~V}$ (vs. $\mathrm{Ag} / \mathrm{AgCl}$ in 3.3 $\mathrm{M}$ saturated $\mathrm{KCl}$ at $25^{\circ} \mathrm{C}$ ), but this theoretical potential is not between the practical anodic and cathodic potential. This deviation is attributed to activation overpotential arising from electron transfer processes. Reverse electrodialysis is necessary to minimize all types of overpotentials to get higher performance. Thus, it is needed to use electrode materials with minimum activation overpotential for reverse electrodialysis.

The detail information obtained from cyclic voltammograms is summarized in Table 1. The important parameters of a cyclic voltammogram are the magnitudes of the anodic peak current $\left(i_{p a}\right)$ and cathodic peak current $\left(i_{p c}\right)$, and the anodic peak potential $\left(E_{p a}\right)$ and cathodic peak potential $\left(E_{p c}\right)$. Commonly, the formal reduction potential for the redox couple is often used as the average of the forward and return peak potentials when the electron transfer process is reversible and the diffusion coefficients for the oxidized and reduced forms are the same. The formal reduction potential $\left(E^{\circ \prime}\right)$ for a reversible couple is centered between $E_{p a}$ and $E_{p c}$ $\left(E^{\circ \prime}=\left(E_{p a}+E_{p c}\right) / 2\right)$. If the reaction is reversible, then the separation in the peak potentials $\left(\Delta E_{p}\right)$ is close to $58 /$ $n \mathrm{mV}$ (at $25^{\circ} \mathrm{C}$ ). Thus, the number of electrons transferred in the electrode reaction $(n)$ for a reversible couple can be determined from the separation between the peak potentials. Slow electron transfer at the electrode surface (called irreversibility) causes the peak separation to increase. ${ }^{5,6)}$ The metal electrodes such as $\mathrm{Au}$ and $\mathrm{Pt}$ (from $\mathrm{Pt} / \mathrm{C}$ ) show relatively better reversibility, but the carbon electrodes such as $\mathrm{AC}$ and $\mathrm{CNF}$ indicate slower electron transfer. Interestingly, the Vulcan electrode showed different behaviors, that is, the similar number of electrons taking part in to the metal electrodes. In addition, the formal potential of the Vulcan electrode is the most similar to the theoretical formal potential of $\mathrm{Fe}(\mathrm{CN})_{6}{ }^{4-} / \mathrm{Fe}(\mathrm{CN})_{6}{ }^{3-}$ which is $0.162 \mathrm{~V}$ (vs. $\mathrm{Ag} /$ $\mathrm{AgCl}$ in $3.3 \mathrm{M}$ saturated $\mathrm{KCl}$ at $25^{\circ} \mathrm{C}$ ). It infers that the Vulcan electrode has the lowest activation overpotential for the redox couple. The magnitude of anodic and cathodic peak currents of $\mathrm{Au}, \mathrm{AC}$ and $\mathrm{CNF}$ is higher than those of $\mathrm{Pt}$ and Vulcan, but the capacitive current of $\mathrm{Au}, \mathrm{AC}$ and $\mathrm{CNF}$ is also significant. Thus, their cyclic voltammograms shown in Fig. 3 have no sharply increasing or decreasing behavior after peak currents. Even though the Pt and Vulcan electrodes show low magnitude of anodic and cathodic peak currents, their cyclic voltammograms represent very reversible cyclic voltammetric characteristics. It is also in good agreement with the higher $\mathrm{n}$ value. It can be concluded that among the electrodes investigated in this study the Vulcan can be a good candidate as electrode material for reverse electrodialysis using the $\mathrm{Fe}(\mathrm{CN})_{6}{ }^{4-} / \mathrm{Fe}(\mathrm{CN})_{6}{ }^{3-}$ redox couple.

Table 1. Anodic and cathodic peak potentials $\left(E_{p}\right)$, peak current densities $\left(i_{p}\right)$ and formal potentials $\left(E^{\circ \prime}\right)$ of the voltammograms measured at various electrode materials

\begin{tabular}{|c|c|c|c|c|c|c|c|}
\hline \multirow{2}{*}{$\begin{array}{l}\text { Electrode } \\
\text { material }\end{array}$} & $\mathrm{E}_{\mathrm{pa}}(\mathrm{V})$ & $\mathrm{E}_{\mathrm{pc}}$ & $\Delta \mathrm{E}_{\mathrm{p}}$ & $\mathrm{E}^{\circ 1}$ & \multirow{2}{*}{$\begin{array}{l}\mathrm{n} \\
-\end{array}$} & $\mathrm{i}_{\mathrm{pa}}$ & $\mathrm{i}_{\mathrm{pc}}$ \\
\hline & \multicolumn{4}{|c|}{ (V) } & & \multicolumn{2}{|c|}{$\left(\mathrm{mA} \mathrm{cm}^{-2}\right)$} \\
\hline $\mathrm{Au}$ & 0.333 & 0.216 & 0.12 & 0.274 & 0.50 & 13.7 & 13.4 \\
\hline $\mathrm{Pt} / \mathrm{C}$ & 0.322 & 0.206 & 0.12 & 0.264 & 0.51 & 7.52 & 7.82 \\
\hline $\mathrm{AC}$ & 0.373 & 0.152 & 0.22 & 0.262 & 0.27 & 9.27 & 11.2 \\
\hline $\mathrm{CNF}$ & 0.350 & 0.176 & 0.17 & 0.263 & 0.34 & 12.0 & 14.3 \\
\hline Vulcan & 0.310 & 0.201 & 0.11 & 0.256 & 0.54 & 7.20 & 7.46 \\
\hline
\end{tabular}

* The a and $\mathrm{c}$ at subscripts of $\mathrm{E}$ and $\mathrm{i}$ denote anodic and cathodic values. 
Taking into account kinetic aspects of the redox reactions at the Vulcan electrode, the easier the redox species reach to the electrode surface, the faster electrons is transferred to and from the electrode surface. Thus, it is important to determine the concentration of redox species for reverse electrodialysis since low concentration of redox couples brings about low kinetics and excess use of redox species causes an increase in cost. Fig. 4 shows the cyclic voltammograms of the $\mathrm{Fe}(\mathrm{CN})_{6}{ }^{4-} / \mathrm{Fe}(\mathrm{CN})_{6}{ }^{3-}$ redox couple for the Vulcan electrode with respect to the concentration of the redox couple in the range of 5 to $50 \mathrm{mM}$. All the cyclic voltammograms show good symmetric shape to represent reversibility of the redox couple at the Vulcan electrode. Anodic and cathodic peak potentials of the cyclic voltammograms shown in Fig. 4 are summarized in Table 2. Peak

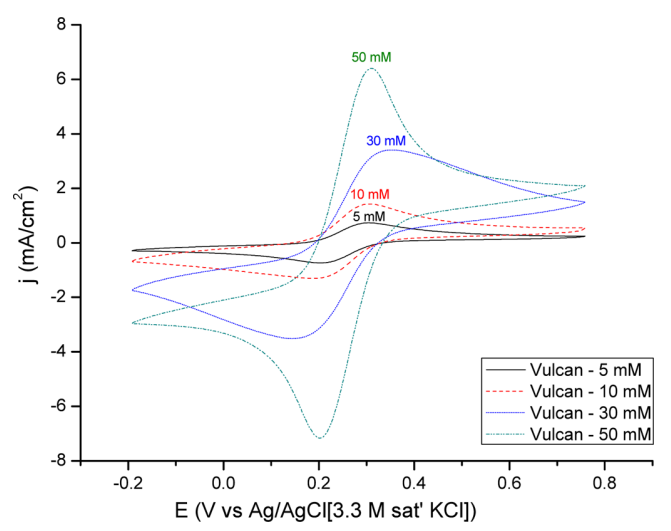

Fig. 4. Cyclic voltammograms of the Vulcan electrode with various concentrations $(5,10,30$ and $50 \mathrm{mM})$ of $\mathrm{Fe}(\mathrm{CN})_{6}{ }^{4-} / \mathrm{Fe}(\mathrm{CN})_{6}{ }^{3-}$ in $1 \mathrm{M} \mathrm{Na}_{2} \mathrm{SO}_{4}$.

Table 2. Anodic and cathodic peak potentials $\left(E_{p}\right)$ and formal potentials $\left(E^{\circ \prime}\right)$ of cyclic voltammograms measured at the Vulcan electrode with various concentrations of $\mathrm{Fe}(\mathrm{CN})_{6}{ }^{4-} / \mathrm{Fe}(\mathrm{CN})_{6}{ }^{3-}$ in $1 \mathrm{M} \mathrm{Na}_{2} \mathrm{SO}_{4}$

\begin{tabular}{cccc}
\hline \multirow{2}{*}{ Concentration $(\mathrm{M})$} & $\mathrm{E}_{\mathrm{pa}}$ & $\mathrm{E}_{\mathrm{pc}}$ & $\mathrm{E}^{\mathrm{O}}$ \\
\cline { 2 - 4 } & & $(\mathrm{V})$ & \\
\hline 0.005 & 0.304 & 0.205 & 0.255 \\
0.01 & 0.306 & 0.188 & 0.247 \\
0.03 & 0.353 & 0.144 & 0.248 \\
0.05 & 0.310 & 0.201 & 0.256 \\
\hline
\end{tabular}

* The a and $\mathrm{c}$ at subscripts of $\mathrm{E}$ denote anodic and cathodic potentials. potentials of cyclic voltammograms are independent on the concentration of electroactive species. Except those from the voltammogram measured at $0.03 \mathrm{M}$ of the $\mathrm{Fe}(\mathrm{CN})_{6}{ }^{4-} / \mathrm{Fe}(\mathrm{CN})_{6}{ }^{3-}$ redox couple, the independence of peak potentials on the concentration of the $\mathrm{Fe}(\mathrm{CN})_{6}{ }^{4-}$ / $\mathrm{Fe}(\mathrm{CN})_{6}{ }^{3-}$ electrolyte is shown. For all the concentrations the similar formal potentials also confirm the evidence indicating that the system is electrochemically reversible.

For a reversible reaction, the concentration is related to peak current by the Randles-Sevcik expression (at $25^{\circ} \mathrm{C}$ ):

$$
\mathrm{i}_{\mathrm{p}}=2.686 \times 10^{5} \mathrm{n}^{3 / 2} \mathrm{Ac}_{\mathrm{o}} \mathrm{D}^{1 / 2} \mathrm{v}^{1 / 2}
$$

where $i_{p}$ is the peak current in amps, $A$ is the electrode area $\left(\mathrm{cm}^{2}\right)$, D is the diffusion coefficient $\left(\mathrm{cm}^{2} \mathrm{~s}^{-1}\right), \mathrm{c}_{\mathrm{o}}$ is the concentration in $\mathrm{mol} \mathrm{cm} \mathrm{cm}^{-3}, \mathrm{n}$ is the number of moles of electrons transferred in the reaction, $\mathrm{v}$ is the scan rate in $\mathrm{V} \mathrm{s}^{-1}{ }^{1}$ ) As expected, it is clearly shown in Fig. 5 that higher anodic as well as cathodic peak currents are measured as the concentration of the redox couple increases and the both peak currents are directly proportional to concentration. According to the Randles-Sevcik equation, the diffusion coefficients of the redox couple on the Vulcan electrode during cathodic and anodic reactions are calculated to be $4.46 \times 10^{-8}$ and $4.59 \times 10^{-8} \mathrm{~cm}^{2} \mathrm{~s}^{-1}$, respectively. For comparison, the

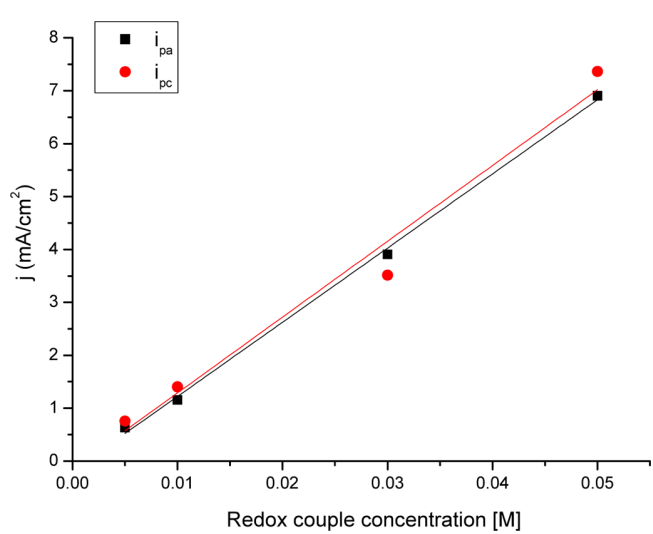

Fig. 5. Peak current densities from the cyclic voltammograms of the Vulcan electrode with various concentrations $(5,10,30$ and $50 \mathrm{mM})$ of $\mathrm{Fe}(\mathrm{CN})_{6}{ }^{4-}$, $\mathrm{Fe}(\mathrm{CN})_{6}{ }^{3-}$ in $1 \mathrm{M} \mathrm{Na}_{2} \mathrm{SO}_{4}$. 
very similar diffusion coefficients on the Pt electrode (from $\mathrm{Pt} / \mathrm{C}$ ) during cathodic and anodic reactions are also obtained to be $5.53 \times 10^{-8}$ and $5.49 \times 10^{-8} \mathrm{~cm}^{2} \mathrm{~s}^{-1}$, respectively. It is in the good agreement with the higher peak current densities indicated in Table 1 .

As a result, Vulcan and $\mathrm{Pt}$ electrodes are promising candidates for reverse electrodialysis in terms of overpotential, reversibility and peak current densities (diffusion coefficients). From a cost point of view, Vulcan is the best electrode material for reverse electrodialysis among various electrode materials investigated in this study since it shows the lowest overpotential based on formal potentials and similar anodic and cathodic current densities to the Pt electrode. In addition, Vulcan having nano-scale diameter $(30 \sim 40 \mathrm{~nm})$ is able to form porous electrode structure which brings about high electroactive surface area.

\section{Conclusions}

The reverse electrodialysis is a promising energy conversion device converting salinity gradient into electricity. Nowadays, the system can be used in the hybrid system of seawater desalination plants consisting of reverse and forward osmosis since seawater is much concentrated after reverse and forward osmosis processes. In order to enhance the performance of reverse electrodialysis, much effort has to be focused to minimize the Ohmic resistance of ion-exchange membranes and the activation resistance arising from electrodes as well as to maximize mass transfer rate kinetically through the ion-exchange membranes and at the electrodes. In this study, the various electrode materials for reverse electrodialysis were investigated in the $\mathrm{Fe}(\mathrm{CN})_{6}{ }^{4-}$ / $\mathrm{Fe}(\mathrm{CN})_{6}{ }^{3-}$ redox couple. The equilibrium and kinetic aspects of various electrodes were studied in terms of cyclic voltammetry. As a result, Vulcan and $\mathrm{Pt}$ (from $\mathrm{Pt} / \mathrm{C}$ ) showed to have similar activation overpotential and lower than the other electrode materials in equilibrium, but $\mathrm{Pt}$ was preferred kinetically due to slightly higher anodic and cathodic current densities than those of Vulcan among $\mathrm{Au}$, Vulcan supported $\mathrm{Pt}(\mathrm{Pt} / \mathrm{C})$, activated carbon, carbon nanofiber, Vulcan. Since Vulcan and Pt represented very similar electrochemical behaviors, both can be good candidates as electrode material for reverse electrodialysis. Considering cost aspect, it can be concluded that Vulcan is the best electrode material among the electrode materials examined in this study.

\section{Acknowledgements}

This work was supported by the 2012 research grant funded by Taeyoung E\&C.

\section{References}

1. J. W. Post, 'Blue Energy: electricity production from salinity gradients by reverse electrodialysis', $\mathrm{PhD}$ thesis (2009).

2. J. W. Post, J. Veerman, H. V. M. Hamelers, G. J. W. Euverink, S. J. Metz, K. Nymeijer, C. J. N. Buisman, 'Salinity-gradient power: evaluation of pressure-retarded osmosis and reverse electrodialysis', J. Membr. Sci., 288, 218 (2007).

3. J. Veerman, J. W. Post, M. Saakes, S. J. Metz, G. J. Harmsen, 'Reducing power losses caused by ionic shortcut currents in reverse electrodialysis stacks by a validated model', J. Membr. Sci., 310, 418 (2008).

4. S.-K. Ryu, Y.-W. Choi, C.-S. Kim, T.-H. Yang, H.-S. Kim, J.-S. Park, 'Preparation and characterization of ionic liquid-based electrodes for high temperature fuel cells using cyclic voltammetry', J. Kor. Electrochem. Soc., 16, 1(2013).

5. G. A. Mabbott, 'An introduction to cyclic voltammetry', J. Chem. Edu., 60, 697 (1983).

6. P. T. Kissinger and W. R. Heineman, 'Cyclic voltammetry', J. Chem. Edu., 60, 702 (1983). 